2

3

4

5

6

7

8

9

\title{
Family communication about donor conception: a qualitative study with lesbian parents
}

H. Van Parys ${ }^{1}$, E. Wyverkens ${ }^{1}$, V. Provoost ${ }^{2}$, P. De Sutter ${ }^{3}$, G. Pennings ${ }^{2}$, \& A. Buysse ${ }^{1}$.

${ }^{1}$ Ghent University, Faculty of Psychology and Educational Sciences, Gent, Belgium.

${ }^{2}$ Ghent University, Bioethics Institute Ghent, Gent, Belgium.

${ }^{3}$ Ghent University Hospital, Department of Reproductive Medicine, Gent, Belgium.

Funding: The project is funded by the Special Research Fund of Ghent University, Belgium.

Acknowledgments: We thank all the families for participating in this study. All the other members of the research team are acknowledged for their efforts in recruitment, interviewing, transcribing and team discussions: An Ravelingien, Inez Raes, Isabelle Stuyver, Sara Somers. The main researcher was H.V.P., the first author of the paper. E.W., V.P., and A.B. provided feedback during all phases of the analysis. G.P., A.B. and P.D.S. (the supervisors of this research project) and V.P. (the coordinator) were involved in the design of the study. P.D.S was also involved in the organization of the recruitment at the Ghent University Hospital.

\section{Correspondence: hanna.vanparys@ugent.be}


In this qualitative study of ten lesbian couples who built their families through anonymous donor conception, we explore how lesbian parents experience the communication about the donor conception within the family. While for these families 'disclosure' of donor conception is often seen as evident, the way parents and children discuss this subject and how this is experienced by the parents themselves has not received much research attention. In order to meet this gap in the literature, in-depth interviews with lesbian couples were conducted. An Interpretative Phenomenological Analysis showed that this family communication process can be understood within the broader relational context of parent-child relationships. Even though parents handled this family communication in many different ways, these were all inspired by the same motives: acting in the child's best interest and - on a more implicit level maintaining the good relations within the family. Furthermore, parents left the initiative for talking about the DC mostly to the child. Overall, parents aimed at constructing a donor conception narrative that they considered acceptable for both the children and themselves. They used different strategies, such as gradual disclosure, limiting the meaning of the donor, and justifying the donor conception. Building an acceptable donor conception narrative was sometimes challenged by influences from the social environment. In the discussion, we relate this qualitative systemic study to the broader issues of selective disclosure and bidirectionality within families.

\section{Keywords}

Parent-Child Relations; Disclosure; Homosexuality, Female; Qualitative Research 
Currently, assisted reproductive technologies such as treatment with donor sperm are becoming more and more widespread and both heterosexual and homosexual families seem to approach the topic with more openness in their families in recent years (e.g., Beeson, Jennings, \& Kramer, 2011; Paul \& Berger, 2007; Stevens, Perry, Burston, Golombok, \& Golding, 2003). A number of recent empirical studies have focused on the question whether children would like to receive (identifiable) information about the donor and/or contact with the donor and their reasons for that (Blyth, Crawshaw, Frith, \& Jones, 2012). However, information is lacking about how families deal with the shared understanding that the children are donor-conceived in their daily life. This study concentrates on lesbian parenthood after Donor Conception (DC) and starts from the question: 'How do lesbian parents talk about the DC with their school-age children?'

\section{Research Focus on Children's Well-Being}

In recent years, research about lesbian parenthood has focused on the psychological well-being of children growing up in these families. Although Regnerus (2012) found more negative outcomes (on emotional, social, as well as relational outcome variables) for grownup children of lesbian families compared to grown-up children in families with still-married heterosexual parents, the majority of the studies shows similar developmental outcomes for both groups. In a review article including studies with both convenience samples and representative samples, Patterson (2006) concluded that children parented by lesbian couples have an overall healthy development. Several studies have shown that children of lesbian households have similar developmental outcomes compared to children in heterosexual families, for instance, in terms of psychological adjustment (Tasker, 2005), progress while attending primary school (Rosenfeld, 2010), and academic achievement (Wainright, Russell, \& Patterson, 2004). When it comes to peer relationships, Van Gelderen (2012) reported a homophobic stigmatization in half of the 17-year old participants $(n=78)$. However, Tasker 
(2005) suggested that children raised by lesbian couples were no more likely to be bullied than children in hetero families. According to Tasker (2005), no differences were found between lesbian and heterosexual families with regard to the quality of family relationships. Furthermore, Patterson (2006) in her review stated that for the child's well-being, family interactions and the quality of family relationships are more important than family structure or sexual orientation of the parents.

\section{Family Communication about the DC}

Offspring of lesbian parents are thought to find out about their DC origins earlier than offspring of heterosexual parents (Beeson et al., 2011). Many authors have considered the issue of disclosing DC in lesbian families as obvious and straightforward (Baetens \& Brewaeys, 2001; Jadva, Freeman, Kramer, \& Golombok, 2009; Vanfraussen, PonjaertKristoffersen, \& Brewaeys 2001). However, little is known about how the DC is discussed with the children in the family (Goldberg \& Allen, 2013). Furthermore, the parents' presuppositions, expectations, or feelings about the disclosure did not receive much research attention. According to Haimes and Weiner, however, (2000) the rationale for telling and the choice of what to tell is almost never straightforward as it touches upon the meaning of social and genetic ties.

Some studies generated findings that inform us about this family communication process to a certain extent. Stevens et al. (2003) found that the birth story for the child was mostly based on the child's questions and that mothers took the child's age into account when informing them about the DC. Furthermore, parents described it as a gradual, spontaneous disclosure process in which they tried to make sure that the child did not find the DC strange or weird (Vanfraussen et al., 2001). The starting point for discussing the DC seemed to be the family structure: having two mothers and no father. In another study on family functioning, Vanfraussen et al. (2003b) made a distinction between general communication (e.g. about 
school) and emotional communication (e.g. about problems with friends). However, no reference was made to family communication about the DC.

With regard to the need for more information about the donor, half of the children seemed satisfied with the birth story and did not desire more information about the donor (Vanfraussen et al., 2003a). For children who either desired non-identifying or identifying information, the main reason was getting to know oneself better. In a study with 11 grown-up children with a known donor, Goldberg and Allen (2013) found that the donor position ranged from 'just donor' to 'father'. The contact preferences and actual contact with the donor varied from 'no contact', to 'currently moving in with the donor'. Even though the participants were informed about the known donation by their parents, parents' disclosure was not entirely transparent: children insisted on receiving identifying information about the donor before they were actually given access to this information.

\section{Current Study}

While there are a few studies focusing on the disclosure of the conception (e.g., Stevens et al., 2003) and children's needs for information about the DC (e.g., Vanfraussen et al., 2003a), a broader study on family members' experience of this communication process is lacking. The current study focuses on how lesbian parents and their children handle the subject of the DC in their daily family communication. In this explorative study, we focused on the parents and we investigated how they describe and experience the family communication about the DC. Interpretative Phenomenological Analyses methodology (Smith, Flowers, \& Larkin, 2009) was used because of its focus on the lived experience and how participants make sense of their experiences. The experience of family relations is considered as a research area that is suitable for IPA (e.g., Harris, Pistrang, \& Barker, 2006; Smith, 1999). 
The present study is embedded in an interdisciplinary qualitative research project, combining bioethical, medical, and psychological viewpoints. The project was set up to investigate the meaning of genetic and non-genetic parenthood for families using Assisted Reproductive Technologies. This study is situated in Belgium, where lesbian couples can marry and co-parent adoption is allowed since 2006. Recently, social mothers are granted the same legal status as fathers in a heterosexual relationship. This means that no adoption procedure is required anymore. However, since the participants in our study gave birth 7 to 10 years ago, the older legislation was still in force.

\section{Method}

\section{Description of the Sample}

Ten lesbian couples (20 participants) were recruited via the Department of Reproductive Medicine of the Ghent University Hospital. Between 2002 and 2004, 42 lesbian couples were accepted for treatment with anonymous donor sperm at the Department of Reproductive Medicine and were now eligible for the study based on the following criteria: Belgian, Dutch speaking, live birth, and no intra-partner oocyte donation. The counselor of the Department (who saw the participants at the time of the fertility treatment, 7 to 10 years ago) contacted sixteen couples based on the child's age (the couples with the eldest child were contacted first) in order to be able to include ten. Five couples could not be included due to inadequate contact information or language difficulties. One couple did not call back after receiving info about the study protocol. The other 26 couples were not contacted. All couples gave birth for the first time between 2002 and 2005, which means that the oldest child was between seven and ten years old. The women had no children from previous relationships. Participants lived in the Flemish part of Belgium and identified as female, lesbian and white. Table 1 provides information on the participants' characteristics, including the children's pseudonyms and age range. Approval by the Ethics Committee of Ghent University Hospital 
was obtained. Participants gave their written informed consent at the time of the interview.

142 All participants were recruited at the same hospital and received the same 'non directive' 143 counseling. The current legislation in Belgium is based on donor anonymity but also allows non-anonymous donation when both donor and recipients give their prior agreement.

145 Participants in this study all used anonymous donation.

\section{Procedure}

Participants were recruited in October 2012 and couple interviews were performed between October and December 2012 at the location of their preference: the Department of Reproductive Medicine of the Ghent University Hospital (1) or their homes (9). The first and the second author each performed five interviews based on the same semi-structured interview guide, which included predominantly open questions about participants' thoughts on and experiences with different aspects of parenthood after DC treatment. As part of the interview, the issues of family communication and DC disclosure to the child were discussed. In six families one or more children were present during a part of the interview. This context factor was taken into account when interpreting the data by keeping track of the moments when the child was present in relation to what the parents were expressing on the one hand and by explicitly coding parent-child interactions that were relevant for the research question on the other hand. The in-depth semi-structured interviews lasted on average 90 minutes. The interviews were audiotaped and transcribed verbatim using pseudonyms. We offered participants the possibility to contact their counselor at the fertility clinic in case questions or psychological needs arose during or after the interview.

\section{Data Analysis Process}

Qualitative analysis was performed using Interpretative Phenomenological Analysis (IPA), involving a detailed step-by-step analysis of each case before turning to the level of comparison across cases. First, reading through the transcript, descriptive and interpretative 
notes were made in order to obtain familiarity with the cases and enhance interpretation of the data (Smith et al., 2009). The next stage consisted of a first coding based on the annotated transcript. In this first coding, the first author looked for patterns and connections across the data. Subsequently, the codes were clustered into themes and subthemes according to conceptual similarities and oppositions. This case-by-case analysis was supported by MAXQDA qualitative data analysis software. Software programs like this do not offer analysis tools. Rather, they are used to organize the data according to the analysis of the researchers. Using the MAXQDA outputs, a comparison across cases was performed, identifying overarching themes and higher-order themes. In the next phase, each theme was described and illustrated using appropriate quotes from the interviews. This way, we held on to the idiographic focus of IPA while formulating ideas that apply to the whole (or parts of) the sample.

In order to put the parents' narrative accounts into perspective and to discuss deeper layers of the parents' experiences, 'hermeneutics of faith' and 'hermeneutics of suspicion' (Josselson, 2004) were alternated. Hermeneutics of faith can be seen as 'giving voice' to the participants and using their own words, while hermeneutics of suspicion imply that some layers of the interpretation do not refer to what parents literally told us but are a reflection of a careful comparison of various accounts (Josselson, 2004). To improve the validity and the trustworthiness of our research, an auditing process was conducted. At several points in the analysis, a team of auditors (second, third and last author) was called upon, inviting them to challenge the way the first author had constructed categories and a conceptual framework (Hill, Thompson \& Nutt-Williams, 1997). Based on extensive research reports, these auditors questioned whether the analysis had been conducted systematically and transparently, and whether the research report - including a conceptual model of the data - was credible (Smith 
et al., 2009). Discrepancies as well as gaps in the analysis were identified and adjusted, which significantly promoted the depth of the analysis.

\section{Results}

The IPA analysis resulted in four themes. The relational context is presented as the framework in which the other three themes can be situated and understood. The second theme describes how parents perceive the child's questions on the topic of DC and how they sometimes handle them in an ambiguous way. A third theme involves the strategies the parents used to install an acceptable DC narrative. A last common theme for which we provide evidence is the connection between family communication and communication with the wider social context.

\section{The Relational Context: Trying to be a Good Parent}

When we asked parents how they experienced family communication about the DC, they made it clear that 'the DC' in their opinion was not the heart of the matter. Rather, their main concern was building the family and creating close relationships between parents and children. Family communication about the DC could be seen within this broader relational context; it is embedded in a process of monitoring the family relationships. Parents tried to talk about the DC in such a way that it would not impede their relationship with the children. Kate: I prefer that they [the children] start to talk about it, because that way you know it's on their mind. Now I have no clue. If you start talking about it yourself, you wonder if they like it or if they think: 'What is she going on about?'

Whereas Kate feared talking about the DC too soon or at an inappropriate moment, and the harm this could cause her child, Rose thought it was important to anticipate these questions: "Because by the time the child poses the question, a lot of things already went through his or her mind." Rose' opinion can be situated within her attempts to facilitate a trusting 
relationship in which everything can be discussed openly. She wanted to avoid that the child created his/her own (unfavorable) story about the DC, which in turn could endanger their solid relational base. Even though these two visions reveal two completely different strategies, both couples referred to their child's best interest.

In line with this focus on good relational bonds, parents expressed certain fears and sensitivities. In general, parents presented themselves as open and reliable towards the child. Monica: When something's wrong, no matter what, he can come to us. And I think that's really important for a child, that when something's wrong, or if you have certain questions, that you can talk to your parents. That you're not held back...

At the same time, parents expressed their uncertainty about whether they would succeed in creating this openness overall, for instance with regard to communication about the DC.

Sara: I'm convinced that we'll be able to talk about it. That it's not going to be like they have concerns which they don't dare mention. Uhm, I really don't want that. I would love to be the kind of parent that's open to all our children's questions.

Feelings of uncertainty seemed to be related to the concern that the children would not accept their choice of building a family through DC. Even when their children seemed fine with it at the moment, the parents feared future conflicts with their children because they might experience it as an injustice that they cannot know their biological father. In this respect, they were also afraid that the child would end up questioning the co-parent's authority as a parent. Apart from feelings of uncertainty, parents also emphasized their responsibility with regard to the child's well-being and anticipated future difficulties:

Sara: While another child in puberty may be angry with his parents because he doesn't get enough pocket money, our children might get all the more angry because we've put them in a situation where they have no father. 
In order to cope with this uncertainty, parents sometimes sought reassurance from their child(ren).

Kate: And then I said [to the son]: 'There is somebody who has given a sperm cell to the hospital. But that is not your dad. Because we don't know, let's say, that's someone who's anonymous, who we don't know, and you don't know him either.' 'So I won't know him?' I said: 'No you won't know him'. I said: 'Does that bother you?' I had asked him that before. He said: 'No, because I have Mummy.'

The question 'Does that bother you?' can be perceived as an attempt to seek reassurance from the child. According to the parent's account, the child gave his mother the reassurance she was looking for by confirming the relational bond with the co-parent and by indicating that he was not preoccupied with getting to know the donor. Similarly, another couple asked their child whether he "missed his father at times." Throughout the interview (during which the child was present), there were some indications that the child was thinking about the donor and that he was curious about who this person was. This question was somewhat directive in so far as the parent not only expected but also hoped that the child would come to deny it. On a content level, the question shows the parents' concerns about whether their child thinks about the donor and how often. However, it can also have the more relational dimension of seeking confirmation that their relationship was strong enough without the presence of a father. In this way, parents partly made room to discuss the DC while they also sought to strengthen the perspective that they were doing fine as a family and that the DC did not endanger that. These feelings of uncertainty and responsibility and the more general attempt to maintain good relational bonds serve as the context to interpret and understand the three remaining themes.

\section{Giving the Child's Questions a Central Position}


All couples explicitly mentioned the child's questions as a cue to start talking about the DC and to adjust the story to the dialogue that unfolds. Some couples waited for the child's queries about the way they were conceived to initiate talk about this issue. Retrospective questioning of the counseling revealed that participants thought the counselor had advised 'to postpone talking about the DC until the child starts to ask questions about it' (which presumably would happen around the age of four). Some couples referred to this advice when explaining how they handled the child's questions: about and that is that you never answer more than what they [the children] are asking advice. Also, it seemed that in their experience, they shifted a part of the responsibility for 'doing a good job as a parent' to the counselor. When the child asked questions, parents were very careful in answering them, aiming at 'giving the correct answer.' Also, parents seemed to 283 be careful not to tell too much to the child. The next quote shows how certain terms were brought up by the parents (for instance 'sperm'), and while being fully aware that the children did not know these terms, they did not explain the term but left it to the child to ask for clarification: 

Nicole: Well, they know they don't have a dad, they have a friendly man who delivered sperm. We talk about sperm even though they don't know what it is. As long as they don't go into further detail, we don't talk about it. But the moment they ask something, we respond. When they look in the booklet and they ask 'What's this?', we say 'Well, that's a sperm tube.' Apart from that, they haven't asked anything else.

Waiting for the child's questions to talk about it and giving only restricted answers seems to constrain the parent-child communication about this topic.

While the child's questions got a prominent place, some parents held rather strict views about what could be considered a proper question. For instance, with one couple, when the child asked about the parents' choice in who would be the biological parent, the parents regarded this as a 'silly question', and not a starting point to talk about the DC. During the interview, the parents realized that their son did ask several questions, although they had mentioned previously that he had not.

Martha: Yes, well, if you look at it that way, he did ask a couple of questions now and then, like 'Why?' and uhm.

Lexi: Yes, but you don't realize it, you see?

In addition, parents seemed to look for cues from their children that validated their disclosure decisions: that, for now, their answers were sufficient and their children's needs for information were met. Finally, some parents saw no need to talk about it: "We don't raise the subject all the time. I find it difficult to say to the children: 'Let's talk.' That's not necessary, you know?" (Ysa)

Overall, parents stated that, against their expectations, they did not receive many questions from their children. In addition, they had also expected these questions earlier. These expectations were partly raised by their recollection of the counselor's message that the child would start asking questions at a certain point. For some parents, the child's questions 
could be alienating or confusing. They did not always feel ready to give an appropriate answer right away: "At first there's a bit of chaos in your head. Like, how are we gonna handle this?" (Monica). Lisa explained that the questions can come unexpectedly:

We never had that with Tim, and then all of a sudden she [younger daughter] - even though she's so much younger - comes to us with these questions. And then we look at each other and think: 'Oops, what's going on?'

Starting from the experience with their oldest child, the youngest child's questions came out of nowhere and left them feeling confused. The last quote illustrates the child's influence and the bi-directionality of this communication process. Not only their parental intentions, but also the child's characteristics seem to determine how the interactions about the DC were shaped.

In sum, parents seemed to have a rather ambiguous attitude towards the child's questions: they saw the questions as a cue to talk; however, when confronted with the questions, they handled them in a rather restricted way or struggled to find a good answer. The communication about the DC can be seen as a complex interplay between: a) the parents' perception of the child's need for information; b) the perceived risks of harm to the child due to the disclosure (strategy); and c) the extent to which parents feel comfortable talking about it and consider it to be necessary.

\section{Installing an Acceptable DC Narrative}

Parents tried to create a DC narrative that was both plausible and satisfactory for the child(ren) and themselves. In this respect, some parents initiated the dialogue about the DC with their child(ren) proactively. They anticipated on the child's questions and started to explain the DC. This 'openness' was motivated by the wish to prevent secrets (and feelings of betrayal) and to install an 'always-knowing' in the child. Talking about the DC from an early 
age seemed to be an important strategy to sculpture the child's perspective on the DC ('they grew up with it') and his/her acceptance of this procedure:

Rose: I think it's important that you guide them a little bit. They're allowed to ask questions, but you say: 'Look, this is how it is. It's a bit different, but that doesn't mean it's bad.'

Some parents also argued that a general openness (in the social environment) about the child being donor conceived was a reason to be open towards the child as well.

In order to meet the goal of 'installing an acceptable DC narrative' different strategies were described: 1) gradual disclosure, 2) differentiating between the donor and a dad, and 3) justifying the DC.

Choosing gradual disclosure. Parents were careful both with regard to what they said to their children as to when they said it. First of all, there was some 'gradation' in what was told; the conception narrative was built through the use of different words and emphases. Eight couples mentioned the donor at some point in the narrative, whereas two couples deliberately chose to wait until a later moment to include talk about the donor. For instance, one couple only mentioned that 'an injection' was administered to the biological mother, without stating the content of the injection, let alone its origin. Consequently, in these narratives, the donor was (temporarily) not mentioned.

Mary: Actually he [the son] hasn't made that connection yet, and we also haven't yet explained to him that the syringe came from a certain someone. That someone isn't in the picture yet, as far as he is concerned. So, in fact he hasn't been able to ask questions about that so far.

As stated in the previous theme, parents seemed to leave the initiative for talking about the donor (conception) to the child. However, in this quote, Mary simultaneously acknowledged that it was impossible for the child to ask questions about it when they had not introduced the 
subject in the first place. Mary said she wished to postpone talking about the donor until their child was mature enough to understand, both on a cognitive and on an emotional level. In this respect, these parents wanted to carefully monitor the child's reception of the story and his maturity to handle it.

Mary: The moment you start talking about it, you have a sense of whether or not your child is with you - whether he understands, listens and goes along with the story. (...) When you feel that he's with you, you can go on, but if you feel he doesn't know what you're talking about, then you better stop there.

These parents were sensitive to the child's reactions and aimed at following his pace so they would not 'lose him' nor have the impression that their relational bond was hampered (cfr. theme 1). In addition, they also waited to inform their son until he was capable of respecting family boundaries with regard to this sensitive information, as they expected him not to share the details with people outside the family. One couple mentioned a box containing written messages that close relatives wrote when the child was baptized. They planned to give this box to the child when he/she reached the age of 12 . They perceived this as a moment to explain the child more about the DC because at that moment a strong parent-child connection would be guaranteed. This was viewed as a buffer against potential negative reactions of the child when he/she became more aware of the DC and the existence of a donor.

Some parents appeared to be very inventive and looked for alternative ways to make the DC more 'conceivable' for the child. For instance, in two families where they knew the donor was Danish, a trip to Denmark was planned as a way to give the child the opportunity to get to know his/her so-called 'roots'. Furthermore, one couple made scrapbooks for each of the children to support their conception story. Lastly, one couple took their children to a farm to witness an insemination of cows. 
Limiting the meaning of the donor. Some couples clearly differentiated between a donor and a 'father' in order to make sure that the donor did not come to play an important role in their child's conception narrative.

Mary: That it's somebody who was just a little part of the process, only in the very beginning, but who doesn't feature in the rest of the story. Not in the upbringing, not in the guidance, not in 'being there'. So that, in the end, he had no further role in Charlie's life story.

Kim: We always tell him: 'It's a donor, not a dad'. Because he... he has the tendency to say: 'I wonder what my daddy looks like.' But I tell him: 'It's not a dad, really. It's a man who gave his sperm cells, he's a donor, so that we could become pregnant.'

By limiting his meaning, they aimed at managing how their child thinks about the donor. In this way, they avoided threats to the family cohesion and their sense of 'being a family'. In addition, parents sometimes referred to the anonymity of the donor as a reason to not elaborate on the donor.

Mia: But apart from that [selection criteria for the donor], we don't know anything about him. And we should keep it like that. And if they ask: 'Why aren't we allowed to know that?', then I say: 'That's, that's how it is, that's the condition'. But he [their son] does understand, really.

Justifying DC. Anticipated feelings of guilt and (fear of) the possible reproach from the child played a role in some parents' decision to talk about the DC early on.

Nicole: The kids will never be in a position to say: 'How come you didn't tell us?'. They will never be in a position to reproach us, because they will have always known. their choice for DC. For instance, one couple kept a diary before and during the process of the 
DC treatment. This diary could then serve as a means to inform as well as explain their choice for creating a family if the child were to question this choice or the parental authority of the co-parent. In one interview where the son was present, a parent tried to convince her son of the value of this technique:

Lauren: It's someone who lives in Denmark, from the Danish [sperm] bank, you know. And we say: "Mummy and Mom both have eggs, we didn't have any seed, so we went to the hospital to get a seed, right?" And the man from Denmark delivers the seeds to the hospital. It's good that there are people like that, huh, sweetie? So then we bought a seed.

Walter: But I do think it sounds strange!

Lauren: It does sound a bit strange, but it's good that it exists, isn't it?

\section{Social Context as Stimulus and Challenge}

Parents explained that communication about the DC was not limited to the context of the family. Rather, the social context 'entered' the family communication in different ways, both via the child and via the parents. Parents indicated that their children sometimes came home with questions either informed by interactions with peers or through events at school (such as Father's Day).

Kim: He once asked: "How come I have two mummies and no dad?"

Mia: That was around Father's Day (...). They were making things for Father's Day at school and they don't have a father, right, they don't have a dad (...). They have a Mom and a Mummy. And well, then they start raising questions, see?

They remembered that at the time of treatment, the counselor urged them to think about the way they would handle the family communication about the DC. Parents still felt challenged at times when friends and colleagues asked questions that were in some cases invoked by the media. 
Liz: And at work? It's not really an issue, but some think it's just logical that there is a mummy and a dad. (...) There was an article in the newspaper, about someone who was a single mother and she didn't mention 'father' but used the word 'donor' instead. They [the colleagues] said: 'How can you ...? You can't say that!'. While I said: 'Uhm, well, that's actually what we do at home'.

Finally, also the interview itself seemed to challenge the parents in the sense that it brought the DC 'under attention' while this topic usually did not come to the surface. To Sandy, realizing that the family was built through DC was somehow not compatible with her daily experience of having a harmonious, complete family. the same time, parents presented themselves as open towards the children with regard to their origins. This openness was mainly conceived as 'being willing to answer the child's questions' and entailed certain restrictions: questions were defined in a strict way, they were not stimulated, and answers seemed to fit with the belief that information should be given at the right moment. In general, parents left the initiative for (a sometimes rather restricted form of) talking about the DC to the child. Feelings of uncertainty and responsibility with regard to the DC sometimes made it hard to be sensitive to the child's cues pointing at his or her interest in the subject (even when there were no straightforward questions from the child). 
Furthermore, parents tried to structure the conception narrative in such a way that it was an

461 acceptable narrative (“a tale they can live with"; Rober, Walravens, \& Versteynen, 2012) for both the children and themselves. Parents tried to 'install' this narrative by stressing certain elements (e.g., 'we are different but equally good', 'donor is not a dad'), by monitoring the child's reception of the conception narrative, and by adjusting it when deemed necessary. The tendency to differentiate between the donor and a father was also found in the literature (e.g., Haimes \& Weiner, 2000; Perlesz et al., 2006). Furthermore, the influence of the social context on the family communication was recognized. This context was an extra challenge in the gradual building of the family conception narrative.

\section{Gradual Disclosure and Restricted Dialogue}

The first theme suggests that family communication about the DC cannot be pictured outside the context of managing family relationships. The data revealed that there was gradual disclosure of the conception story within the lesbian families. Gradual disclosure means that parents build up the conception narrative gradually with their children and reveal more information as the child grows older. This implies that, while talking about this subject, parents monitored their child's reactions. Moreover, it also entails a cyclical process in which things can be told and retold and gradually obtain their meaning within the family.

The idea of gradual disclosure is opposed to the research tendency to classify disclosure decisions as 'disclosure' or 'non-disclosure', a distinction that is generally made in the literature about heterosexual parents using donor gametes to conceive (e.g., Daniels, Grace, \& Gillett, 2011; Hahn \& Rosenberg, 2002; Shehab et al., 2008). Only a few studies with heterosexual parents focus on the continuum of disclosure (Daniels, 1995; Readings, Blake, Casey, Jadva, \& Golombok, 2011) and on the ways in which parents communicate about the DC with their children (Mac Dougall, Becker, Scheib, \& Nachtigall, 2007). The concept of selective disclosure can help us further understand this communication process in 
lesbian families. Selective disclosure means that people disclose (sensitive) information to others close to them in a selective way (Rober et al., 2012; Rober \& Rosenblatt, 2013), for instance, by means of topic avoidance. Topic avoidance refers to dealing with topics such as negative experiences, deviant choices, or failures in one's life by avoiding them in daily conversation (Caughlin \& Afifi, 2004). Even though parenthood after DC was not at all perceived as a negative experience or a failure by the parents, some parents considered it as a 'deviant choice' in comparison to societal norms and felt responsible for this particular family context. Uncertainty stemming from this feeling of responsibility might have incited parents to choose not to talk about the DC until the child reached a certain age or started asking questions.

We found a tension between the general idea of being open towards the children and the practice of handling the subject in a rather restricted way. In the cases where a dialogue was started, this often appeared to be a restricted dialogue, in which there were subtle limitations on what could be asked or told and the extent to which there was 'dialogical meaning making' (Gergen, 1999) about the donor and the DC. Furthermore, when parents' experiences were different from their expectation (that their children would start asking questions at a certain point), this did not serve as a cue for them to change their strategy. They rather perceived the absence of questions from the child as a confirmation of the wait-and-see strategy. 'If they want to know, they will ask'. This 'caution' or 'reluctance' can be related to the first theme again. It is possible that these parents aimed at building strong family ties and consolidating these bonds before giving explanation about the involvement of the donor, as they did not have control over the meaning the child will give to this donor. In addition, some parents preferred not to be confronted with the donor themselves. As a result they might try to limit, control, or at least monitor the communication around this subject in a first stage.

\section{Bidirectionality of Disclosure}



parents and is directed towards the children. Parents felt challenged by their children's

512

513 questions and at the same time they adapted their communication strategy to the child's response to the story to a certain extent. Theories of bidirectional influences in parent-child relationships (Kuczynski, 2003; Kuczynski \& Parkin, 2007) indicate that maintaining a positive long term relationship with the child is considered in managing this subject in the family at present (De Mol \& Buysse, 2008). Our analysis supported the mutual influence of parents and children when it came to disclosure: first of all, the child's silence was often responded with silence from the parents' side. Second, the child's questions were responded with a (rather limited) answer of the parents. Third, sometimes the child's silence was responded by parents' explanations as they hoped to avoid the possible future reproach for not telling them. In that case, parents installed the DC narrative proactively. Anticipated guilt could play a role here. Parents may have acted in certain ways in order to avoid feelings of guilt in the future, for instance, for putting their child in an 'alternative' family situation and as such transgressing a general accepted moral norm (Wang, 2011). Fourth, parents reported differences between their children, which gave rise to different approaches to handling the subject of the DC. These findings add to the literature on disclosure strategies (e.g., Mac Dougall et al., 2007). It seems that when parents opt for the 'right time' disclosure strategy in the context of lesbian parenthood, they not only rely on the child's age and cognitive abilities but also (or even especially) on their questions. In a way, the child holds the key to disclosure. While Stevens et al. (2003) already pointed this out, our study adds complexity to the finding given that the inconsistency between allocating a key role to the child's questions and not creating a dialogical space where these questions can be raised, is also addressed.

Even when parents have a 'functional' narrative about the DC in their family, this narrative can be challenged when confronted with the world outside. Parents described how 
the family communication was inspired, influenced, and challenged by the social context. In this respect, it is noteworthy that Vanfraussen et al. (2002) studied how children in lesbian families handled questions from peers and how they actively presented their families to people in the outside world. While Vanfraussen et al. (2002) did not mention the mutual influence of extra- and intra-familial communication, the results of the current study point at this interrelation. Congruent with Haimes and Weiner (2000) we conclude that social relationships are shaping the family communication, especially when it comes to issues related to the family identity.

\section{Implications for Clinicians and Future Research}

In the literature on counseling, talking about DC has been regarded as an isolated issue and little attention has been given to the broader family communication and the managing of parent-child relationships. The findings of this exploratory study suggest that we should broaden our perspective and also include this relational focus in the counseling sessions at the fertility clinic. While parents usually experience a certain level of self-confidence when it comes to explaining things to their children (Jensen, Gulbrandsen, Mossige, Reichelt, \& Tjersland, 2005), here it seems that parents experienced more uncertainty and that they were eager to find advice or guidance to hold on to, especially from a professional in the field. On a societal level, there seems to be a lack of 'scripts' to talk about the DC with the children. Jensen (2005) noted that when topics are rarely addressed, families lack 'already practiced rules or habits for conversation' to lean on to (p. 1408). Counselors can play a role here and support parents in their search for a script, especially by recognizing and normalizing their feelings of uncertainty and helping them to recognize the child's cues, while respecting choices with regard to gradations of telling and of representing the donor in the family narrative. 

families networks so a possible bias could be prevented. The rigorous analysis of rich data can be considered as another asset in comparison to the literature on this topic. However, this study also has some limitations. First, we have to take into account that the participants were counseled 7-10 years ago. The counseling session is a conversation with the psychologist of the Department of Reproductive Medicine, prior to treatment (mandatory at Ghent University Hospital). The counseling discourse now (which is more focused on openness) may differ from the guidelines counselors followed back then. At that time the counselors' guidelines were 'non directive' which means that neither openness, nor secrecy was advanced. you manage as parents?' This might give rise to parents trying to prove themselves as good parents. While parents' positive self-presentations might reflect their benign intentions as parents, it can also be an expression of their need to construct a consistent self-image as 'a good parent'. Related to this, it is important to note that we gathered recollections of conversations and not the conversations themselves. Some level of selection bias in what the 574 parents chose to present in the interview may be present. In this respect, gaining the perspectives of the children of these parents would further contribute to our understanding of 576 this family communication process. A future study including both parents' and children's 577 voices, using dyadic interview analysis methodology, will inform us about the way the family 578 communication is actually perceived by the child and will further explore the bidirectional 579 influences that are involved.

Third, as this is a qualitative study, statistical generalizability of the findings of this study is not applicable. Rather, we aim at maximizing the transferability and the theoretical generalizability (Flick, 2014) of the findings. Using the current information on the context of 
the interviews and the sample, readers, academics and policy-makers can assess whether the findings of this study could possibly be meaningful to other contexts.

Finally, conducting a study on communication about DC holds the risk that this communication is unnecessarily problematized. In a way, similar mechanisms can be observed with communication about other 'sensitive' subjects in the family, such as for instance sexuality. According to Rober et al. (2012), there is a bias towards openness in our Western society. We can ask whether openness is always required in the current context. However, most importantly, we should acknowledge the complexity of family communication on these sensitive issues in full (Rober \& Rosenblatt, 2013).

\section{Conclusion}

Overall, DC and the donor were not regularly talked about in these families. By talking about the DC in a 'restricted' way, the donor was also kept at a distance. This seems to be functional as family life revolves around creating connections together rather than representing an unknown donor figure. When family communication about the DC did occur, it seems that this could take many different forms and was a complex interplay of extra-familial influences, the child's agency and perceived needs, the parent's preferences and emotions, societal discourse, etc. Often the strategy parents chose was motivated by the wish to act in the child's best interest and to maintain good relations within the family. By exploring previously unknown family communication processes, this research adds to our general understanding of lesbian led families and lesbian relationships (Gotta et al., 2011). Both qualitative and quantitative studies are needed to investigate, for instance, the bidirectional aspects of this parent-child communication process.

\section{References}



update of the knowledge with regard to lesbian mother families. Human Reproduction

608

609

610 Update, 7, 512-519. doi: 10.1093/humupd/7.5.512

Beeson, D. R., Jennings, P. K., \& Kramer, W. (2011). Offspring searching for their sperm donors: How family type shapes the process. Human reproduction, 26, 2415-2424. doi:10.1093/humrep/der202

Blyth, E., Crawshaw, M., Frith, L., \& Jones, C. (2012). Donor-conceived people's views and experiences of their genetic origins: A critical analysis of the research evidence. Journal of Law \& Medicine, 19, 769-789.

Caughlin, J. P., \& Afifi, W. A. (2004). When is topic avoidance unsatisfying? Examining moderators of the association between avoidance and dissatisfaction. Human Communication Research, 30, 479-513. doi: 10.1111/j.1468-2958.2004.tb00742.x

Daniels, K. R. (1995). Telling donor insemination offspring about their conception: The nature of couples' decision-making. Social Science \& Medicine, 40, 1213-1220. doi: $10.1016 / 0277-9536(94) 00251-\mathrm{N}$

Daniels K. R., Grace V. M., \& Gillett W. R. (2011). Factors associated with parents' decisions to tell their adult offspring about the offspring's donor conception. Human Reproduction, 26, 2783 - 2790. doi: 10.1093/humrep/der247

De Mol, J., \& Buysse, A. (2008). The phenomenology of children's influence on parents. Journal of Family Therapy, 30, 163-193. doi: 10.1111/j.1467-6427.2008.00424.x

Flick, U. (2013). The SAGE handbook of qualitative data analysis. London: Sage.

Hahn, S. J., \& Rosenberg, M. C. (2002). The disclosure decisions of parents who conceive children using donor eggs. Journal of Obstetric, Gynecologic, and Neonatal Nursing, 31, 283-293. doi: 10.1111/j.1552-6909.2002.tb00050.x

Gergen, K. (1999). An invitation to social construction. London, UK: Sage. 

2000. Family Process, 50, 353-376. doi: 10.1111/j.1545-5300.2011.01365.x doi:10.1111/1467-9566.00215 process in depression: A phenomenological analysis. Psychology and Psychotherapy: Theory, Research and Practice, 79, 1-21.

Hill, C. E., Thompson, B. J., \& Nutt-Williams, E. (1997). A guide to conducting 643 consensual qualitative research. Counseling Psychologist, 25, 517-572. doi: 10.1177/0011000097254001.

645 Jadva, V., Freeman, T., Kramer, W., \& Golombok, S. (2009). The experiences of 646 adolescents and adults conceived by sperm donation: Comparisons by age of disclosure and 647 family type. Human Reproduction, 24, 1909-1919. doi: 10.1093/humrep/dep110

648 Jensen, T. K., Gulbrandsen, W., Mossige, S., Reichelt, S., \& Tjersland, O. A. 649 (2005). Reporting possible sexual abuse: A qualitative study on children's perspectives and 650 the context for disclosure. Child Abuse \& Neglect, 29, 1395-1413. doi: $651 \quad 10.1016 /$ j.chiabu.2005.07.004

652 Josselson, R. (2004). The hermeneutics of faith and the hermeneutics of suspicion. 653 Narrative Inquiry, 14, 1-28. doi: 10.1075/ni.14.1.01jos 
654

655

656

657

658

659

660

661

662

663

664

665

666

667

668

669

670

671

672

673

674

675

676

Kuczynski, L., \& Parkin, M. (2007). Agency and bidirectionality in socialization: Interactions, transactions, and relational dialectics. In J. E. Grusec \& P. Hastings (Eds.), Handbook of socialization (pp. 259-283). New York, NY: NY Guilford.

Kuczynski, L. (2003). Handbook of dynamics in parent-child relations. Thousand Oaks, CA: SAGE.

Mac Dougall, K., Becker, G., Scheib, J. E., \& Nachtigall, R. D. (2007). Strategies for disclosure: How parents approach telling their children that they were conceived with donor gametes. Fertility \& Sterility, 87, 524-533. doi: 10.1016/j.fertnstert.2006.07.1514

Patterson, C. J., 2006. Children of lesbians and gay men. Journal of Marriage and the Family, 62, 1052-1069.

Paul, M. S., \& Berger, R. (2007). Topic avoidance and family functioning in families conceived with donor insemination. Human Reproduction, 22, 2566-2571. doi:10.1093/humrep/dem174

Perlesz, A., Brown, R., Lindsay, J., McNair, R., deVause, D., \& Pittsf, M. (2006). Family in transition: Parents, children and grandparents in lesbian families give meaning to 'doing family'. Journal of Family Therapy, 28, 175 - 199. doi: 10.1111/j.1467-6427.2006.00345.x

Readings, J., Blake, L., Casey, P., Jadva, V., \& Golombok, S. (2011). Secrecy, disclosure and everything in-between: Decisions of parents of children conceived by donor insemination, egg donation and surrogacy. Reproductive BioMedicine Online, 22, 485-495. doi: 10.1016/j.rbmo.2011.01.014

Regnerus, M. (2012). How different are the adult children of parents who have same-sex relationships? Findings from the New Family Structures Study. Social Science Research, 41, 752-770. 
Rober, P., \& Rosenblatt, P. C. (2013). Selective disclosure in a first conversation about a family death in James Agee's novel A Death in the Family. Death Studies, 37, 172-194. doi: $10.1080 / 07481187.2011 .628555$

Rober, P., Walravens, G., \& Versteynen, L. (2012). "In search of a tale they can live with": About loss, family secrets and selective disclosure. Journal of Marital and Family Therapy, 38, 529-541. doi: 10.1111/j.1752-0606.2011.00237.x

Rosenfeld, M. J., 2010. Nontraditional families and childhood progress through school. Demography, 47, 755-775.

Shehab, D., Duff, J., Pasch, L. A., Mac Dougall, K., Scheib, J. E., \& Nachtigall, R. D. (2008). How parents whose children have been conceived with donor gametes make their disclosure decision: Contexts, influences, and couple dynamics. Fertility \& Sterility, 89, 179187. doi:10.1016/j.fertnstert.2007.02.046

Smith, J. A. (1999). Towards a relational self: Social engagement during pregnancy and psychological preparation for motherhood. British Journal of Social Psychology, 38, 409-426.

Smith, J. A., Flowers, P., \& Larkin, M. (2009). Interpretative Phenomenological Analysis: Theory, method and research. London, UK: Sage.

Stevens, M., Perry, B., Burston, A., Golombok, S., \& Golding, J. (2003). Openness in lesbian-mother families regarding mother's sexual orientation and child's conception by donor insemination. Journal of Reproductive and Infant Psychology, 21, 347-362. doi: $10.1080 / 02646830310001622141$

Tasker, F. (2005). Lesbian mothers, gay fathers, and their children: A review. Developmental and Behavioral Pediatrics, 26, 224-240. doi: 10.1097/00004703-20050600000012

Vanfraussen, K., Ponjaert-Kristoffersen, I., \& Brewaeys, A. (2001). An attempt to reconstruct children's donor concept : A comparison between children's and lesbian parents' 
702

attitudes towards donor anonymity. Human Reproduction, 16, 2019-2025. doi: 10.1093/humrep/16.9.2019

704

705

706

707

708

709

710

711

712

713

714

715

716

717

718

719

720

721

722

723

724

725

Vanfraussen, K., Ponjaert-Kristoffersen, I., \& Brewaeys, A. (2002). What does it mean for youngsters to grow up in a lesbian family created by means of donor insemination? Journal of Reproductive and Infant Psychology, 20, 237-252. doi:10.1080/0264683021000033165

Vanfraussen, K., Ponjaert-Kristoffersen, I., \& Brewaeys, A. (2003a). Why do children want to know more about the donor? The experience of youngsters raised in lesbian families. Journal of Psychosomatic Obstetrics and Gynaecology, 24, 31-38. doi: $10.3109 / 01674820309042798$

Vanfraussen, K., Ponjaert-Kristoffersen, I., \& Brewaeys, A. (2003b). Family functioning in lesbian families created by donor insemination. American Journal of Orthopsychiatry, 73, 7890. doi: 10.1037/0002-9432.73.1.78

Van Gelderen, L., Bos, H. M. W., Gartrell, N., Hermanns, J., \& Perrin, E. C. (2012). Quality of life of adolescents raised from birth by lesbian mothers: The US National Longitudinal Family Study. Journal of Developmental and Behavioral Pediatrics, 33, 17-23. doi:10.1097/DBP.0b013e31823b62af

Wainright, J. L., Russell, S. T., \& Patterson, C. J. (2004). Psychosocial adjustment, school outcomes, and romantic relationships of adolescents with same-sex parents, Child Development, 75, 1886-1898. doi: 10.1111/j.1467-8624.2004.00823.x

Wang, X. (2011). The role of anticipated guilt in intentions to register as organ donors and to discuss organ donation with family. Health Communication, 26, 683-690. doi: 10.1080/10410236.2011.563350 


\begin{tabular}{llll}
\hline N & Biological mother & Social mother & Children (years of age, range) \\
01 & Sarah & Lisa & Tim, Lynn $(6-9)$ \\
02 & Mia and Kim & Mia and Kim & Tom, Eva $(4-9)$ \\
03 & Rose & Liz & Ben, Jessica $(7-9)$ \\
04 & Nicole & Angela & Travis, Rian, Antonio, Milo (1-9) \\
05 & Mary & Monica & Charlie $(9)$ \\
06 & Lauren & Jill & Walter $(9)$ \\
07 & Beth & Lydia & Neil, Florence $(6-9)$ \\
08 & Kate & Sandy & Kenny, Marilou $(7-8)$ \\
09 & Martha & Lexi & Bart, Mathilda $(8-9)$ \\
10 & Ysa & Anni & Brenda, Geena, Louise $(5-9)$ \\
\hline
\end{tabular}

